\title{
POLÍTICAS PÚBLICAS E CRÍTICA QUEER: ALGUMAS QUESTÕES SOBRE IDENTIDADE LGBT
}

\author{
POLÍTICAS PÚBLICAS Y CRÍTICA QUEER: ALGUNAS CUESTIONES SOBRE \\ IDENTIDAD LGBT \\ PUBLIC POLICIES AND QUEER CRITICS: SOME QUESTIONS ABOUT \\ LGBT IDENTITY
}

\author{
Juliana Vieira Sampaio \\ Universidade Federal do Ceará, Fortaleza/CE e Universidade Federal de Pernambuco, Recife/PE, Brasil
}

e Idilva Maria Pires Germano

Universidade Federal do Ceará, Fortaleza/CE, Brasil

\begin{abstract}
RESUMO
Na década de 1980, o movimento LGBT no Brasil iniciou uma parceria política com o Estado a fim de enfrentar o surto da AIDS. O sucesso dessas ações contribuiu para novas pautas políticas visando melhor assistência à população LGBT. Tais políticas nos últimos anos ampliaram-se, porém adaptando-se ao modo de representação política vigente, uma política identitária essencialista. O objetivo deste trabalho é discutir como o essencialismo que fundamenta a sexopolítica é negociado nas políticas públicas LGBT e como uma "identidade estratégica" pode afetar os modos de viver daqueles que não se encaixam no padrão heteronormativo. Numa perspectiva discursiva crítica, cinco documentos de políticas públicas foram examinados, com o apoio de quadro conceitual foucaultiano e da Teoria Queer. Concluímos que uma política das multidões queer sinaliza formas de ação ainda mais radicais e potentes.
\end{abstract}

Palavras-chave: políticas públicas; teoria queer; movimento LGBT; identidade.

\section{RESUMEN}

En la década de 1980, el movimiento LGBT en Brasil comenzó una asociación política con el Estado para hacer frente a la epidemia del SIDA. El éxito de estas acciones se ha traducido en nuevas directrices políticas para ayudar las personas LGBT. Estas políticas en los últimos años se han ampliado, pero adaptándose a la modalidad predominante de la representación política, una política de identidad esencialista. Este trabajo tiene el objetivo de discutir cómo el esencialismo que subyace a la sexopolítica se negocia en las políticas públicas LGBT y cómo una "identidad estratégica" puede afectar las formas de vida de aquellos que no se ajustan a la norma heteronormativa. Desde el punto de vista discursivo crítico, se examinaron cinco documentos de políticas públicas LGBT, con el apoyo del marco conceptual de Foucault y de la teoría queer. Llegamos a la conclusión de que una política de multitud queer indica formas de acción aún más radicales y potentes.

Palabras clave: políticas públicas; teoría queer; movimiento LGBT; identidad.

\begin{abstract}
In the eighties, the LGBT movement in Brazil began a political partnership with the State in order to address the AIDS epidemic. The success of those actions resulted in new political agendas aiming to ensure better care for LGBT people. Recent policies were expanded but had to adapt to the current mode of political representation, an essencialist type of identity politics. This paper aims to discuss how the essencialism that grounds sexpolitics is negotiated in LGBT public policies and how a "strategic identity" can affect the ways of living of those who don't fit heteronormative standards. From a critical discursive perspective, five documents of LGBT public policies were studied based on Foucauldian and Queer Theory conceptual frames. We conclude that queer multitude politics may signal more radical and strong forms of political action.
\end{abstract}

Keywords: public policies; queer theory; LGBT movement; identity. 


\section{Construindo uma identidade LGBT}

A história da despatologização da homossexualidade é muito recente. Apenas em 1973 ela deixa de ser oficialmente uma doença psiquiátrica e é excluída do Manual Diagnóstico e Estatístico de Transtornos Mentais (DSM). A despatologização da homossexualidade pelo saber médico propiciou a construção de uma nova perspectiva científica e moral sobre a população gay. Refutando o viés patológico da homossexualidade, em vigor desde o século XIX (Foucault, 1988/2009a), a mudança implicou entende-la como fenômeno normal, em termos estatísticos. Como atesta o famoso estudo de Kinsey, essa normalidade foi compreendida numa perspectiva probabilística, considerando a frequência de casos na população geral. Essas evidências científicas permitiram algumas mudanças na relação entre sexualidade e tradições morais, como a perspectiva do sexo antes do casamento, adultério e homossexualidade (Gamson, 2006).

O movimento gay da década de 1980, inspirado nos movimentos feministas e étnicos da década anterior, entre outras reivindicações, buscava modificar a percepção de que os homossexuais eram seres exóticos e estranhos que contrastavam com o heterossexual normal e respeitável. A estratégia utilizada foi "recuperar uma subjetividade gay ou lésbica que havia sido historicamente negada." (Gamson, 2006, p.349). Perseguindo seus direitos civis numa conjuntura de lutas emancipatórias, o movimento contribuiu para a construção de uma noção essencializada do "eu gay" e de uma forma "autêntica" da subjetividade homossexual. O indivíduo homossexual seria uma variação natural da sexualidade humana, assim como a diversidade étnica, desse modo, gays e lésbicas compartilhariam um passado e um presente comum e independente do momento histórico e cultural da sociedade.

No Brasil, com o surto de HIV/AIDS na década de 1980, o Movimento Homossexual Brasileiro (MHB) construiu parcerias com o Estado a fim de garantir uma melhor assistência à população homossexual vítima da doença. Pelúcio e Miskolci (2009) assinalam que, no início do surto da AIDS, dois em cada cinco infectados tinham relações sexuais frequentes com outros homens, dessa forma a doença foi inicialmente nomeada como GRI (Imunodeficiência Gay Adquirida). Mesmo após sua renomeação para AIDS (Síndrome da Imunodeficiência Adquirida), a fantasia sobre a relação direta entre a homossexualidade e a doença permaneceu. Nesse sentido, o perigo do sexo anal ganhou uma roupagem cientifica e permeada pela higienização da sexualidade. Como explica Miskolci
(2011, p. 49), a epidemia de HIV/AIDS “teve o efeito de repatologizar a homossexualidade em seus novos termos contribuindo para que certas identidades, vistas como perigo para a saúde pública, passassem por um processo de politização controlada.”

De início, com a epidemia, produziu-se em torno do enfrentamento da AIDS uma série de ações voltadas para as pessoas afetadas pelo vírus, como também para possíveis vítimas, entre elas os gays. Essas atividades favoreceram o fortalecimento do movimento homossexual no Brasil. Muitas associações e grupos gays foram fundados nesse período a partir do financiamento de programas governamentais e do apoio de instituições internacionais que combatiam a AIDS (Simões \& Facchini, 2009). De fato, a luta contra a epidemia, num primeiro momento, possibilitou que a homossexualidade ganhasse visibilidade favorecendo o debate em diversos espaços da sociedade:

O "sucesso" no combate à AIDS e o crescimento do movimento LGBT permitiram que se formasse uma "aliança" entre o movimento e os vários níveis de governo no país. Uma das questões apontadas seria de que a população LGBT passa a ter assistência à saúde quando seus indivíduos são reconhecidos pelo Estado como sujeitos "sujos" que precisam ter a sua sexualidade higienizada a partir de um padrão heterossexual. Esse espaço de negociação política originou, desde então, novas demandas e a proposição de projetos de lei em âmbito federal, estadual e municipal, agora não mais atreladas apenas à área da saúde e ao combate da AIDS, mas também nos campos da educação, cultura, trabalho, direitos humanos e outros (Miskolci, 2011).

A área da saúde, desde as iniciativas de controle da epidemia da AIDS nos anos 1980, tem sido privilegiada como foco de políticas públicas para a população LGBT e, nos últimos anos, vem trabalhando com um conjunto de ações que representa uma série de avanços para esse grupo, mas que ainda demonstra enfrentar muitas dificuldades e resistências (Mello, Brito, \& Maroja, 2012). A estratégia do movimento LGBT de reivindicar suas demandas junto ao Poder Executivo recebe críticas diversas, que abrangem não somente os entraves na implementação das normas e projetos de lei voltados para a garantia desses direitos, mas também os fundamentos heteronormativos e essencialistas que tais ações encarnam, bem como seus efeitos.

Mesmo que ampliadas as áreas de atuação das políticas públicas voltadas para a população LGBT, percebe-se que o controle da sexualidade homossexual permanece central e perdura nas políticas de saúde pública, mediante seu foco na prevenção do HIV e 
DST. Ainda que a categoria epidemiológica "grupo de risco" tenha sido substituída por "comportamentos de risco", o binômio DST/AIDS mantem-se atuando como dispositivo que produz a vigilância e a disciplina dos corpos e do prazer na população LGBT, resultando no controle heteronormativo das relações sexuais e afetivas (Pelúcio, 2007; Pelúcio \& Miskolci, 2009). O fenômeno de visibilidade política e social LGBT por via da AIDS é chamado por Pelúcio (2007) de SIDAdanização, termo no qual a troca do "c" pelo "s", e que denuncia uma cidadania alcançada pela repatologização da sexualidade não heterossexual. Para que esse grupo adquira a SIDAdania, precisa partilhar os pressupostos do programa de prevenção de DST/AIDS, compreendendo a responsabilidade que têm sobre si e os cuidados que devem dedicar à saúde, a partir do modelo biomédico.

Uma das ações desenvolvidas pelo governo federal em parceria com a sociedade civil organizada foi o Brasil sem Homofobia: Programa de Combate à Violência e à Discriminação contra GLTB e de Promoção da Cidadania de Homossexuais (Conselho Nacional de Combate à Discriminação, 2004). Esse programa foi construído com o objetivo de combater a homofobia mediante diferentes frentes de ação, nas áreas da educação, saúde, segurança, cultura e trabalho. A partir dessa proposta foram elaborados outros documentos governamentais para atender as especificidades de demanda da população LGBT, como a Política Nacional de Saúde Integral LGBT (Ministério da Saúde, 2010) e o Plano Nacional de Promoção da Cidadania e Direitos Humanos LGBT (Secretaria Especial dos Direitos Humanos, 2009).

É possível notar que, embora essas políticas sejam importantes para assegurar os direitos da população LGBT, envolvem o risco de contribuir para a naturalização de uma identidade gay, fundamentada na irredutibilidade da anatomia e no determinismo biológico. De fato, o conceito de identidade está associado a uma visão dos indivíduos e de coletividades como portadores de características exclusivas e relativamente permanentes, determinadas seja por genes, seja por uma estrutura psicológica, como ocorre na perspectiva psicanalítica (Íñiguez, 2004). Ambos os modelos tendem a compreender a identidade como algo intrínseco ao humano e que faz parte da sua essência. Tal visão, no âmbito das sexualidades, tende a reforçar uma noção coesa de identidade social gay, turvando a heterogeneidade dos modos de viver o desejo e "praticar" a sexualidade. Nesse sentido, a crítica queer adverte como os movimentos baseados na noção de identidade gay (e, portanto, as políticas que resultam desses movimentos) não conseguem contemplar a multidão queer, isto é, a pluralidade de atores e formas de existência que escapam ao padrão heteronormativo. Dissociando a suposta coerência entre sexo, gênero e desejo, o movimento queer mostra como a nossa sociedade, através de diversos dispositivos (instituições, leis, enunciados científicos, políticas etc.) controlam e normatizam a sexualidade a partir de uma heterossexualidade compulsória.

Contraditoriamente, as políticas identitárias de minorias sexuais podem configurar aquilo que Preciado (2011, p. 11) se refere como "sexopolítica", uma forma dominante de biopolítica na atual sociedade capitalista, na qual,

O sexo (os órgãos chamados 'sexuais', as práticas sexuais e também os códigos de masculinidade e de feminilidade, as identidades sexuais normais e desviantes) entra no cálculo do poder, fazendo dos discursos sobre o sexo e das tecnologias de normalização das identidades sexuais um agente de controle da vida.

Em oposição a essa forma de dominação, a proposta é que a sexopolítica deixe de ser um lugar de controle dos corpos para transformar-se em espaço de "criação na qual se sucedem e se justapõem os manifestos feministas, homossexuais, transexuais, intersexuais, transgêneros, chicanas, pós-coloniais... [onde] minorias sexuais tornam-se multidões." (Preciado, 2011, p. 14).

A tentativa de agregar os múltiplos fatores envolvidos é facilmente percebida nas mudanças que a sigla LGBT tem sofrido ao longo do tempo. Determinadas letras foram adicionadas (o B e o T), outras foram retiradas (o S, da antiga sigla GLS) e algumas pretendem entrar (o T e o I, representando transexuais e intersexuais respectivamente). A proposta de uma política da multidão queer difere daquela procedente do coletivo LGBT por não se balizar numa noção de identidade natural homem/mulher ou em práticas sexuais, mas na multiplicidade de corpos que resistem às normas (Preciado, 2011). O queer emerge como efeito do controle da sexualidade, subvertendo toda e qualquer construção identitária e questionando o regime de poder que classifica corpos, práticas e desejos em "normais" e "anormais". Entende que a construção de políticas com base numa identidade sexual limita o público alvo a ser contemplado, como também restringe as possibilidades de se exercer livremente a sexualidade.

Nosso objetivo neste trabalho é discutir como o tipo de compreensão essencialista que fundamenta a política de identidade LGBT e a sexopolítica de modo geral é negociado nas políticas públicas voltadas para 
essa população e de que modo o uso de uma "identidade estratégica" afeta e constrói determinados modos de viver das pessoas que não se encaixam no padrão heteronormativo. Em nossa discussão, remetemos a alguns documentos de políticas públicas recentes voltadas para o público LGBT, destacando trechos que denunciam as contradições da política de identidade sexual: "Brasil Sem Homofobia: Programa de combate à violência e à discriminação contra GLTB e promoção da cidadania homossexual" (Conselho Nacional de Combate à Discriminação, 2004); "Plano nacional de enfrentamento da epidemia de AIDS e das DST entre gays, HSH e travestis" (Ministério da Saúde, 2007); "Plano Nacional de Promoção da Cidadania e Direitos Humanos de Lésbicas, Gays, Bissexuais, Travestis e Transexuais" (Secretaria Especial Dos Direitos Humanos, 2009). "Plano integrado de enfrentamento da feminização da epidemia de AIDS e das DST." (Ministério da Saúde, 2009); "Política Nacional de Saúde Integral de Lésbicas, Gays, Bissexuais, Travestis e Transexuais." (Ministério da Saúde, 2010).

\section{Políticas públicas como práticas discursivas}

As políticas específicas para a população LGBT no Brasil se constroem como uma tentativa de agregar uma "minoria sexual" que não é contemplada pelas políticas existentes, em resposta às reivindicações do movimento LGBT. Contudo, tais políticas, à medida que institucionalizam determinadas demandas, também funcionam como um dispositivo de controle da sexualidade. Os documentos referentes às políticas públicas funcionam como dispositivo de controle, uma vez que produzem práticas e determinam quais os modos de viver que são possíveis ou desejáveis. Para analisarmos de que forma as políticas públicas LGBT contribuem para a construção de identidades sexuais e tornam essas categorias estáticas, valemo-nos do conceito de práticas discursivas, tal como formulado em Foucault e retomado por Spink (2004).

As práticas discursivas referem-se às "maneiras a partir das quais as pessoas produzem sentidos e se posicionam em relações sociais cotidianas" (Spink \& Medrado, 2004, p.45). Estas são permeadas por relações de poder e se materializam em falas e textos mediante uma dinâmica (enunciados e vozes sociais), certas formas (gêneros de fala) e conteúdos (repertórios interpretativos), isto é, o conjunto de "termos, descrições, lugares-comuns e figuras de linguagem usados para construir certas versões de ações, fenômenos e eventos." (p. 47).

A compreensão da linguagem como produtora da realidade, encarnada no conceito de prática discursiva, remonta às contribuições paradigmáticas resultantes do giro linguístico, movimento que conferiu centralidade à linguagem na vida social, realçando sua dimensão performativa (Spink, 2004). É a partir da compreensão da linguagem como ação que são desenvolvidos os estudos das práticas discursivas. O interesse dessas análises é pesquisar de que forma as pessoas produzem sentido e se posicionam em suas relações sociais por meio do uso da linguagem, seja ela institucionalizada ou não. Nesse sentido, a linguagem só adquire significado nas interações sociais e esse significado não é universal ou ahistórico, mas se constrói através das negociações cotidianas.

Nessa perspectiva metodológica é importante ficar atento ao aspecto instituinte do discurso, não apenas à sua regularidade, mas principalmente aos momentos de mudança. As constantes transformações históricas podem ser apreendidas pela dinâmica das práticas discursivas, analisando o que permanece e o que se modifica. O antigo e o novo coexistem em um mesmo período e isso propicia cortes e rupturas. As pesquisas construídas a partir dessa abordagem procuram "observar os fenômenos sociais que tenham como foco a tensão entre a universalidade e a particularidade, entre o consenso e a diversidade, com vistas a produzir uma ferramenta útil para transformações da ordem social." (Spink, 2004, p. 61).

É na tensão entre universalidade e particularidade que analisaremos documentos de domínio público, especificamente políticas públicas LGBT, entendendo-as como práticas discursivas. Tais documentos permitem identificar momentos de "ressignificações, de rupturas, de produção de sentidos, ou seja, ... momentos ativos do uso da linguagem, nos quais convivem tanto a ordem como a diversidade" (Spink, 2004, p.45). O documento de domínio público consiste em uma forma peculiar de prática discursiva, pois geralmente é construído a partir de regras específicas que delimitam que conteúdo deve ser apresentado, a quem é endereçado, quem está autorizado a produzi-lo, bem como sua moldagem em certo gênero discursivo. Nesse sentido, usar tais fontes em pesquisa "trata-se de considerar os documentos em sua articulação com: quem os produziu, em que ocasiões, que interesses estavam em jogo, como são lidos, quem os lê, que propósitos e negociações estavam em jogo etc." (Méllo, Silva, Lima, \& Di Paolo, 2007, p. 30).

$\mathrm{Na}$ perspectiva discursiva, o documento deixa de ser percebido como matéria inerte ao preservar uma história dos acontecimentos e passa a ser compreendido como instância produtora dessa história. O 
documento, assim entendido, transmuta-se em campo de batalha onde problemas materiais e simbólicos são contestados. Desse modo, o uso de documentos na pesquisa não deve limitar-se à sua função de registro histórico, mas admiti-los como um território no qual os processos sociais se fazem presentes e atuantes. Isso implica focalizar os documentos públicos como principal material de análise, evitando seu tratamento como "fontes secundárias" (Méllo, 2006).

Os documentos referentes a políticas públicas, foco da nossa pesquisa, apresentam algumas características particulares que os distinguem de outros documentos de domínio público. Uma das principais diferenças é que esse material tem como proposta estabelecer regras, ordenar, disciplinar e determinar as possibilidades de existência. Esse tipo de documento oficial é importante para a governamentalidade, isto é, "o conjunto constituído pelas instituições, procedimentos, análises e reflexões, cálculos e táticas que permitem exercer esta forma bastante específica de poder, que tem por alvo a população." (Foucault, 1979/2009b, p. 291). As políticas públicas funcionam como uma tática de governo do Estado que permite definir o que é ou não sua competência, além de ser uma forma de controle da população e consequentemente dos indivíduos. Podemos compreender esses documentos como um dos modos de sujeição que vinculam as pessoas a um conjunto de regras ou valores e tornam o espaço público um propagador e atualizador de ideias totalizantes.

Como lembra Foucault (1970/2008), a sexualidade e a política são lugares privilegiados para o discurso, pois nesses espaços a interdição está intimamente ligada ao poder. No caso das políticas públicas LGBT, a sexualidade e a política se "encontram" e é nesse território que se determina quem tem o direito privilegiado de falar sobre o assunto, o que é permitido falar e em que circunstâncias. O discurso, segundo Foucault (1970/2008, p.10), "não é simplesmente aquilo que traduz as lutas ou os sistemas de dominação, mas aquilo por que, pelo que se luta". À medida que as políticas são construídas institui-se como verdade um saber sobre quem são as pessoas LGBT e quais são as suas necessidades.

No Brasil, as políticas públicas LGBT são de modo geral bastante recentes, tendo surgido há menos de quinze anos, contudo já é possível acompanhar algumas mudanças em suas propostas de ação nesse período. Os textos de tais políticas permitem perceber a emergência, consolidação e reestruturação de conhecimentos referentes à compreensão e normatização das sexualidades e modos de vida não heterossexual. Como dito anteriormente, as políticas
LGBT mais antigas estavam geralmente voltadas para o campo da saúde, especificamente para o campo da prevenção, diagnóstico e tratamento de doenças sexualmente transmissíveis (DST) e AIDS (Miskolci, 2011). Os últimos documentos produzidos tem a preocupação de assegurar direitos anteriormente "negados" a essa população, além de promover o debate em outros campos diferentes da saúde, como educação, cultura e lazer (Ministério da Saúde, 2009).

A análise desses documentos permite perceber a luta entre diversos saberes, práticas e instituições na construção das políticas públicas em questão: o campo médico-epidemiológico que determina a prioridade de ações voltadas para as DST, demarcando a particular vulnerabilidade da população de LGBT; os movimentos políticos LGBT demandando outras ações que não se limitem apenas ao incentivo do uso de preservativo; o sistema jurídico, operando num campo minado de tensões para preservar os direitos e a cidadania de pessoas LGBT numa sociedade cujos modelos sexuais e familiares crescentemente se diversificam. A verdade sobre as necessidades das pessoas LGBT, e de quem elas são, vai se desenhando nessa arena entre diferentes formas de saber-poder.

\section{Política pública e identidade: Que sujeitos LGBT são produzidos?}

A compreensão da linguagem como ação mostra de que forma as políticas públicas LGBT constroem uma noção de identidade estável, imputando-a a essa população. A rigidez provocada pela noção de identidade pode ser percebida ao analisarmos o tópico "dúvidas mais frequentes" ao final do Programa Brasil sem Homofobia (Conselho Nacional de Combate à Discriminação, 2004). Nesse espaço do documento são apresentadas definições de identidade sexual, homossexualidade e orientação sexual. O objetivo da análise desses documentos não é afirmar que as definições apresentadas no programa estejam equivocadas, mas argumentar como nessas proposições estão cristalizadas noções de um sexo e gênero natural e binário que são constituintes de uma identidade estável.

Segundo o Programa Brasil sem Homofobia (CNCD, 2004, p.29), identidade sexual é:

o conjunto de características sexuais que diferenciam cada pessoa das demais e que se expressam pelas preferências sexuais, sentimento ou atitudes em relação ao sexo. A identidade sexual é o sentimento de masculinidade ou feminilidade que acompanha a pessoa ao longo da vida. Nem sempre está de acordo com o sexo biológico ou com a genitália da pessoa. 
Essa definição de identidade sexual apresenta uma noção de sexualidade binária, organizando-se a partir de duas categorias, o masculino e o feminino, como se essas fossem "naturais" aos seres humanos e com uma fronteira fixa separando-as. Tal polaridade é constituída a partir da diferença e exclusão, além de ser estabelecida uma hierarquia entre as duas categorias. O feminino é construído a partir da oposição ao padrão masculino, assim como o negro e o homossexual são algo "exterior" ao branco e heterossexual. Essas categorias marcadas pela diferença são transformadas em "exterior”, em excluído (Hall, 2008).

A produção do excluído ou, como teoriza Butler (1993/2008), do "abjeto", ocorre simultaneamente com a produção do sujeito: o "eu" falante é convidado a assumir uma identidade, no caso da sexualidade, uma identificação na matriz heterossexual que impede ou nega outras identificações. Ao determinarmos que há apenas duas formas de exercer a sexualidade, masculina ou feminina, excluímos e destinamos à abjeção corpos que fogem dessa norma. A abjeção constrói uma zona "inabitável", povoada por "não sujeitos" (Butler, 1993/2008, p.19). A política LGBT constituída a partir da noção de identidade, na tentativa de assegurar os direitos de uma população "excluída", termina por criar outras zonas de exclusão.

O texto do Programa Brasil sem Homofobia (CNCD 2004) rompe a correspondência linear entre sexo e identidade sexual ao afirmar que esta "nem sempre está de acordo com o sexo biológico ou com a genitália da pessoa". Para a perspectiva queer, a desconstrução da congruência entre sexo, gênero e desejo é importante, mas é necessário também questionar mais radicalmente as categorizações rotineiras. Teóricos do Movimento Queer, como Judith Butler (1993/2008, 1990/2010) e Beatriz Preciado (2002, 2008, 2011), desafiam-nos a desnaturalizar não só as categorias gênero, orientação sexual e identidade sexual, mas também a própria noção de sexo. O sexo, diferente dos outros conceitos, esteve historicamente ligado a uma materialidade biológica e da natureza, por isso incontestável. A questão é que por muito tempo foi ignorado que a própria categoria natureza também foi construída socialmente:

Anne Fausto-Sterling (2002) e Judith Butler (2008) discutem em seus textos que o conceito de natureza deve ser repensado, pois ele não pode ser entendido como categoria pré-discursiva, como se não houvesse uma história que compõe esta pretensa naturalidade, fazendo as práticas humanas existirem antes mesmo das suas marcas socioculturais. As autoras alertam também para não incidirmos no extremo oposto de entender a natureza apenas como uma superfície de inscrição que espera passivamente assumir o seu significado social. Assim, afirmar que discursos constroem as nossas vidas não é alegar que nele ela se origina, como se bastasse um foco linguístico sem análise de suas condições de existência, estratégias e efeitos. (Méllo \& Sampaio, 2012, p. 6)

A proposta do Movimento Queer não é negar a materialidade dos corpos e cair no reducionismo linguístico, mas é "basicamente uma iniciativa desconstrutiva, que desmonta a noção de um eu definido por algo que se encontra em sua essência, seja este o desejo sexual, a raça, o gênero, a nação ou a classe" (Gamson, 2006, p. 346). A perspectiva alinhada à Teoria Queer coloca em questão a busca compulsória por uma coerência entre sexo, gênero, corpo, desejo e práticas sexuais. O esforço para se atingir tal coerência pode ser observado na proposta do Programa Brasil sem Homofobia (CNCD 2004, p.29), cuja definição de orientação sexual está ligada à busca de uma sexualidade "verdadeira" e intrínseca ao sujeito:

Orientação sexual é a atração afetiva e/ou sexual que uma pessoa sente pela outra. A orientação sexual existe num continuum que varia desde a homossexualidade exclusiva até a heterossexualidade exclusiva, passando pelas diversas formas de bissexualidade. Embora tenhamos a possibilidade de escolher se vamos demonstrar, ou não, os nossos sentimentos, os psicólogos não consideram que a orientação sexual seja uma opção consciente que possa ser modificada por um ato da vontade.

O fato de tal concepção de sexualidade propor uma transitividade entre uma orientação heterossexual e homossexual não exclui a rigidez desse modelo identitário. Spink (2004, p.50) critica a própria noção de identidade e avalia que "identidade é uma noção mais estrutural, mais fixa, mesmo quando pensada no enquadre da metamorfose (Ciampa, 1987). Metamorfose ainda é uma mudança de 'A' para 'B', presume assim um substrato fixo." $\mathrm{O}$ argumento ajuda a compreender como é limitada a noção de orientação sexual que tem como referência pontos fixos, heterossexualidade e homossexualidade, mesmo que seja possível uma variação dentro desse continuum, que passe por "diversas formas de bissexualidade".

O Programa Brasil sem Homofobia (CNCD 2004) busca explicitar que a orientação sexual não é uma escolha, amparando-se inclusive na legitimidade do saber psicológico para fundamentar o argumento. Desse modo, tanto a heterossexualidade como a homossexualidade são transformadas em práticas naturais que fazem parte de uma suposta essência humana. Esse posicionamento, de assegurar que a homossexualidade é tão natural quanto a 
heterossexualidade, é compreensível ao analisarmos que historicamente a primeira foi julgada como um desvio moral a ser corrigido, regulado e punido. Mas se partirmos de um posicionamento absolutamente fluido e contextualizado, podemos compreender que a ação de se autodenominar como heterossexual ou homossexual é desempenhada no processo de interação com o outro e é atravessada por diferentes saberes e poderes. As práticas discursivas produzem não só uma realidade social, como também psicológica.

No mundo moderno, onde se busca compulsoriamente uma sexualidade "verdadeira", afirmar que a orientação e a identidade sexual são uma opção "consciente e um ato de vontade" transforma esse processo de autodesignação numa escolha política (Weeks, 2001). Tal postura diverge do Programa Brasil Sem Homofobia (CNCD, 2004), pois este defende que apenas a expressão da orientação sexual pode ser um ato voluntário. Esse documento acaba restringindo a discussão sobre sexualidade apenas ao campo da interioridade do indivíduo (da sua verdade e natureza) e não problematiza que a afirmação da orientação sexual pode ter uma função política de subverter e desnaturalizar a norma heterossexual. A afirmação da identidade sexual funcionaria do mesmo modo que a "ressignificação" do termo queer, originalmente usado pejorativamente para ofender aqueles que se desviavam das normas de sexo e gênero. Esses sujeitos, em um ato político e de resistência, se apropriaram do termo queer e passaram a utilizá-lo para unir e dar visibilidade a diferentes formas de viver a sexualidade. A proposta é que as pessoas marcadas como queer não se restrinjam a uma população específica, e sim, reúnam aqueles que desconstroem as classificações fixas de identidade (Gamson, 2006).

Ainda no mesmo tópico "dúvidas mais frequentes" do Programa Brasil sem Homofobia (CNCD 2004, p. 30) é apresentada a "classificação de homossexualidade, segundo padrão de conduta e/ ou identidade sexual". Nesse trecho são apresentadas definições dos termos gays, homossexuais, lésbicas, bissexuais, transgêneros e transexuais. Ao construirmos essas categorizações estamos definindo uma noção prévia do que seria a "identidade" gay, transexual e lésbica. Nessa perspectiva parte-se da pressuposição de que esses grupos são homogêneos e todos que se "identificam" com alguma das classificações citadas apresentam desejos e práticas semelhantes.

Quando é definido na política que gays "são indivíduos que, além de se relacionarem afetiva e sexualmente com pessoas do mesmo sexo, têm um estilo de vida de acordo com essa sua preferência, vivendo abertamente sua sexualidade" (CNCD,
2004, p. 30), é construída a noção de que existe um estilo de vida gay, com características específicas que os diferenciam do restante da população (isto é, heterossexual, "normal"). Podemos perceber nessa definição que a homossexualidade deixou de ser relacionada exclusivamente a um ato genital e passou a ser caracterizada por uma identidade coletiva estável, possível mesmo sem a prática sexual. Afirmar a existência de um estilo de vida gay restringe as inúmeras possibilidades de vivência de quem se afasta dos padrões heterossexuais a apenas um conjunto de comportamentos supostamente próprios a essa "comunidade" e guiados por uma estrutura de personalidade comum.

Preciado (2008) afirma que os "critérios psicológicos" utilizados para nos nomearmos "sou homem", "sou homossexual", "sou travesti", "sou gay", "sou mulher", "sou lésbica" são ficções somatopolíticas produzidas por um conjunto de tecnologias de dominação dos corpos. Essas técnicas limitam nossas potencialidades e produzem um saber interior sobre nós mesmos, tomando a forma de desejos, ações, crenças e identidades. A heterossexualidade, nessa perspectiva, não é compreendida apenas como "uma prática sexual, mas como um regime político que faz parte da administração dos corpos e da gestão calculada da vida no âmbito da biopolítica" (Preciado, 2011, p. 12). Dessa forma, a heteronormatividade funciona também como "modelo" para as práticas homossexuais: é desejável que os gays não sejam femininos, "afetados", "deem pinta". Essa conduta "gay masculina" possibilitaria uma "adequação" mais próxima aos padrões de gênero heterossexual. Miskolci (2011) afirma que travestis e transexuais tenderiam a sofrer mais violência justamente por romperem essas fronteiras da sexualidade e não seguirem a estética de gênero dominante.

Essa percepção da sexualidade como algo público surge especificamente em um trecho do documento que trata da manifestação franca das orientações sexuais. O que seria "viver abertamente sua sexualidade" (CNCD, 2004, p. 30)? As práticas sexuais deixam o âmbito da vida privada e passam a ser um assunto de interesse público que deve ser regulado e padronizado. A "saída do armário", movimento iniciado no final da década de 1960, ilustra bem as questões suscitadas por essa exposição da sexualidade. Esse movimento defendia que os homossexuais deveriam revelar para todos a sua orientação sexual, a fim de mostrar para a sociedade em geral que muitos gays faziam parte do seu convívio pessoal e não eram aberrações. Essa divulgação, contudo, diferente do que era propagado, não possibilitava uma vivência livre da sexualidade; 
apenas colocava esses sujeitos noutro espaço do dispositivo da sexualidade, nunca fora dele. Sedgwick (2007) discute que a revelação desse segredo, que tem marcado a vida de homossexuais nas últimas décadas, é constituída por regras contraditórias que limitam a privacidade dessas pessoas. A autora apresenta diversos casos em que a "saída do armário" impõe negociar o que pertence ao espaço público e ao privado e argumenta como essas negociações regem as condutas e os valores da sociedade ocidental contemporânea.

A “epistemologia do armário" (Sedgwick, 2007) desvela outras dificuldades referentes à relação entre condutas sexuais, identidade pessoal e sentimentos de pertencimento coletivo. Como afirma Weeks (2001, p.72), "sentimentos e desejos sexuais são uma coisa, enquanto que a aceitação de uma posição social particular e um organizado senso de si - isto é, uma identidade - é outra. Não existe nenhuma conexão necessária entre comportamento e identidade sexual.”

Nesse sentido, novas categorias surgem para dar conta das diferentes práticas sexuais cujos atores recusam certas formas de identificação disponíveis, como por exemplo, a noção de homens que fazem sexo com homens (HSH). A sigla HSH é utilizada para referir-se a "homens que mantêm relações sexuais com outros homens, independente destes terem identidade sexual homossexual" (CNCD, 2004). Essa categoria já está difundida em diversos estudos epidemiológicos, principalmente nas pesquisas sobre HIV/AIDS, orientando políticas públicas voltadas para esse segmento populacional, como o "Plano Nacional de enfrentamento da epidemia de AIDS e das DST entre gays, HSH e travestis" (Ministério da Saúde, 2007). Independente de assumirem uma posição "passiva" ou "ativa" na relação sexual, as pessoas caracterizadas como HSH não desejam ser associadas à homossexualidade ou à esfera gay. Larissa Pelúcio (2007), em sua tese sobre travestis e prevenção de AIDS, relata que os homens que se relacionam com as travestis (T-lovers) buscam constantemente assegurar a sua heterossexualidade e consequentemente a sua normalidade. Escolher a posição social que irá ocupar, do normal ou abjeto, é extremamente importante numa sociedade heterocentrada, dessa forma os T-lovers não se relacionam com "homem de peito", mas com uma "mulher de pênis".

Essa negociação entre a identidade e o status social também pode ser percebida nos "Planos nacionais de enfrentamento da epidemia de AIDS e das DST" (2007, 2009), citados anteriormente. Em 2007, o Ministério da Saúde lançou dois planos voltados para o combate da AIDS e DST. O primeiro plano estava destinado a ações para enfrentar a feminização da AIDS e outras DST, enquanto o outro plano tinha como público alvo gays, HSH e travestis. O curioso nessas duas políticas é o fato das transexuais serem contempladas pelo primeiro plano e as travestis pelo segundo. A distinção dispõe essas duas categorias, transexuais e travestis, em espaços sociais distintos, mas não é apenas o nome em si que marca essa diferença, e sim os saberes construídos sobre esses indivíduos. Historicamente as transexuais estiveram incluídas na categoria HSH, assim como as travestis, mas nas últimas políticas do governo as transexuais foram assistidas nos documentos voltados para as mulheres. O "Plano integrado de enfrentamento da feminização da epidemia de AIDS e das DST", revisado em 2009, justifica por que as transexuais foram incluídas nessa política:

Um aspecto que compõe os contextos de vulnerabilidade e a feminização da epidemia do HIV/ AIDS e outras DST entre essas mulheres [transexuais] é a sua interface com a iniquidade de gênero, que se traduz frequentemente na idealização romântica das relações sexuais e afetivas, "como se as relações a partir do amor fossem capazes de imunizar a pessoa de qualquer perigo ou vulnerabilidade”. Nessa lógica, a possibilidade de práticas sexuais desprotegidas com seus parceiros e/ou parceiras contribui para uma maior exposição ao risco de infecção pelo HIV/AIDS e outras DST. (Ministério da Saúde, 2009, p. 53, grifo nosso)

Podemos perceber que o texto acima reconhece o feminino nas transexuais por essas idealizarem romanticamente suas relações sexuais e afetivas. A concepção de que as transexuais se identificam "psicologicamente" com o "universo feminino" (são mulheres em um corpo errado) é uma construção do saber médico, que considera a transexualidade uma patologia passível de ser curada pela cirurgia de redesignação sexual. Essa percepção das transexuais como mulheres "presas" em um corpo masculino as diferencia das travestis que, apesar de se identificarem com o feminino, não são "mulheres ou transexuais verdadeiras". Esse feminino naturalizado, tributário de uma essência romântica e passiva, não é questionado nas construções da identidade ou nas políticas públicas.

Essas duas políticas de enfrentamento da AIDS e outras DST, além de serem marcadas pelo binarismo de sexo e gênero - uma política masculina e outra feminina - ainda revelam uma disputa identitária dentro do próprio segmento LGBT no Brasil. As transexuais, diferentemente das travestis, ganharam, pelo menos nessa política, o status de "mulher". A questão que se coloca a partir dessa discussão é qual característica demarcaria exatamente a diferença entre travestis e 
transexuais: seria o diagnóstico médico, a cirurgia de mudança de sexo ou os documentos de identidade? Esse questionamento passa a ter importância quando percebemos que o indivíduo será ou não assistido por determinada política dependendo de qual lado da fronteira de gênero ele se localiza.

De fato, como mostra Foucault (1979/2009b, p.229), a sexualidade em nossa sociedade não é simplesmente o que permite a reprodução, o prazer ou o gozo, mas "o lugar privilegiado em que nossa 'verdade' profunda é lida". Esse lugar privilegiado da sexualidade marca os corpos, não apenas dos considerados desviantes, mas também dos que se localizam na "normalidade". Esse dispositivo determina qual banheiro devemos usar, que roupa vestir, quem desejar, inclusive, qual política irá nos assistir. As tecnologias forjadas pelo saber/poder controlam, transformam e docilizam os nossos corpos. São essas tecnologias que tornam possível a construção de uma identidade gay, lésbica, bissexual ou transexual essencializada. O caráter ficcional dessas categorias não diminui a sua eficácia discursiva, o seu poder político e a sua materialização.

Foucault (1979/2009b) compreende que onde há poder há resistência, desse modo, analisar as condições de existência do poder é uma das formas de fomentar resistência. Resistir implica, entre outras ações, entender que a heterossexualidade compulsória constituinte dos nossos modos de viver não é natural, mas uma construção histórica/discursiva. Assim, não cabe questionar se o poder é legítimo ou ilegítimo, bom ou ruim, mas lutar contra os regimes de normalização e sujeição. A possibilidade de resistência, de recusa a ser o que a sociedade e o Estado determinam, alinhase tanto com as ideias de Foucault como com uma perspectiva queer. Analisando as políticas identitárias, que supõem a existência de uma identidade prévia e essencializada para se constituir, podemos perceber que acabam restringindo os próprios sujeitos que esperam representar e assistir. Podemos pensar na desconstrução dessas identidades como forma de resistência e isso não determinaria a desconstrução da própria política, mas estabeleceria "como político os próprios termos pelos quais a identidade é articulada" (Butler, 1990/2010, p. 213).

\section{Essencialismo estratégico ou uma estratégia não-identitária?}

A história do movimento LGBT no Brasil apresenta uma relação de influência mútua com o Estado, o que tem produzido ganhos e perdas, pois tanto favorece a construção de novas demandas como também torna esse diálogo cada vez menos crítico (Simões \& Facchini, 2009). As mudanças ocorridas nos últimos anos nas letras que compõem a sigla LGBT sinalizam a fragilidade de um movimento político que pauta a sua relação com o Estado a partir de uma noção de identidade que supõe representar uma pluralidade de corpos. As políticas públicas construídas a partir dessa relação demarcam em seu discurso institucionalizado quais corpos podem ser assistidos pelo Estado e quais são os que permanecem na zona de abjeção. Miskolci (2010, p.10) aponta que é urgente "o fim do modelo identitário de letrinhas" com o risco de tornar o movimento cada vez menos plural e democrático.

Em uma sociedade organizada a partir de uma matriz heteronormativa, os corpos ganham o status de sujeito dependendo do território que ocupam, dentro da normalidade ou da aberração. Esses corpos que não se encaixam na heteronormatividade são considerados como um produto imperfeito ou acidentes e acabam exercendo papel de exceção à regularidade da natureza, afinal toda regra possui uma (Preciado, 2002). Dentro dessa lógica, os diferentes são convidados a construir uma identidade que demarca a sua particularidade em meio a uma massa considerada homogênea. Os heterossexuais não precisam declarar ou revelar a sua identidade, pois em nossa sociedade se pressupõe que todos sejam heterossexuais.

A noção de identidade sexual demarca uma posição específica em relação às normas sociais, pois, ainda que não natural, "para muitos, no mundo moderno, é um conceito absolutamente fundamental, oferecendo um sentimento de unidade pessoal, de localização social e até mesmo comprometimento político" (Weeks, 2001, p.70). A partir de uma perspectiva queer, essa declaração identitária pode ser reconstruída por uma demarcação não sexual que se oponha aos regimes de padronização e normalização. A política das multidões queer, proposta por Preciado (2011, p.18), "emerge de uma posição crítica a respeito dos efeitos normalizantes e disciplinares de toda formação identitária, de uma desontologização do sujeito da política de identidades: não há uma base natural ["mulher", "gay" etc.] que possa legitimar a ação política".

Com efeito, as políticas públicas LGBT aqui estudadas se fundamentam em uma noção de identidade sexual natural cuja lógica é a do binarismo de gênero e sexo. Em oposição ao essencialismo das políticas identitárias, Preciado (2011) defende que os corpos não são tão dóceis quanto Foucault imaginava: os corpos são vibráteis e a localização como anormal e perverso pode ser apropriada como um território de potência, 
subversão e resistência. O queer seria ao mesmo tempo uma estratégia pós-identitária e hiperidentitária através da qual os indivíduos que constituíram sua subjetividade pelas marcas da vergonha, xingamento e negatividade ("bicha", "viado", "sapatona" etc.), isso é, pela abjeção, são convidados a transformar essa vivencia em um recurso político. Dessa forma, a política poderia ser pensada para além do interesse de um conjunto de sujeitos prontos e a ideia de uma identidade estável deixaria de ser premissa para as ações do Estado.

Algumas questões surgem da nossa análise sobre as políticas públicas LGBT para as quais não temos uma resposta acabada. Contudo, acreditamos que o movimento queer, ainda que não proponha definir uma direção precisa, é capaz de inspirar o estranhamento de noções arraigadas em nossa cultura e suscitar indagações pertinentes. A negociação do movimento LGBT com o Estado ficaria ameaçada, caso não se recorresse ao discurso de uma identidade sexual para reivindicação de direitos? Seria possível pensar políticas públicas para além da identidade? As políticas públicas construídas para uma dita "minoria" não seriam mais um espaço através do qual o "normal" tolera o diferente?

O risco de uma "despolitização" do movimento LGBT pode, de certo modo, limitar ou impedir as possibilidades de mudança pelo medo de se abandonar o "essencialismo estratégico" que ampara a luta desses segmentos, mas a luta por direitos não precisa sempre partir de modelos oferecidos pelo Estado (Miskolci, 2010). Com efeito, embora sejam notáveis os ganhos obtidos com a adoção de políticas essencialistas no que concerne aos direitos civis, a desconstrução dessa forma de fazer política pode descortinar um horizonte de formas de ação ainda mais potentes. A igualdade não precisa ser alcançada pelo modelo identitário, nem as reivindicações do sujeito político precisam estar associadas a uma suposta verdade oculta no sexo, gênero, formas de sexualidade ou grupos de pertença.

\section{Referências}

Butler, J. (2008). Cuerpos que importan: sobre los limites materiales y dicursivos del "sexo". (A. Bixio, Trad. 2a. ed.) Buenos Aires: Páidos. (Original publicado em 1993)

Butler, J. (2010). Problemas de Gênero: Feminismo e subversão da identidade. (R. Aguiar, Trad. ). Rio de Janeiro: Civilização Brasileira. (Original Publicado em 1990)

Conselho Nacional de Combate à Discriminação.- CNCD (2004). Brasil Sem Homofobia: Programa de combate à violência e à discriminação contra GLTB e promoção da cidadania homossexual. Brasília: Ministério da Saúde.
Ciampa, A.C. (1987). A estória do Severino e a história da Severina. São Paulo: Brasiliense.

Foucault, M. (2008). A ordem do discurso: Aula inaugural no Collège de France. (L. Sampaio, Trad.). São Paulo, Loyola. (Original publicado em 1970)

Foucault, M. (2009a). História da sexualidade I: a vontade de saber. (M. T. C. Albuquerque \& J. A. G. Albuquerque Trads. 19a. ed.) Rio de Janeiro: Graal. (Original publicado em 1988).

Foucault, M. (2009b). Microfisica do Poder. (R. Machado, Trad. 28a. ed.). Rio de Janeiro: Graal. (Original Publicado em 1979).

Gamson, J. (2006). As sexualidades, a teoria queer e a pesquisa qualitativa. In N. K. Denzin \& Y. S. Lincoln. O planejamento da pesquisa qualitativa: teorias e abordagens. (pp. 345362). Porto Alegre: Artmed/Bookman.

Hall, S. (2008). Quem precisa de identidade? In Silva, T.T. (Org.), Identidade e diferença: A perspectiva dos estudos culturais. (T. Silva, Trad. pp. 103-133) Petrópolis, RJ: Vozes.

Íñiguez, L.(2004). Manual de analise do discurso em ciências sociais. V. L. Joscelyne Trad.). Petrópolis, RJ: Vozes.

Mello, L., Brito, W., \& Maroja, D. (2012). Políticas públicas para a população LGBT no Brasil: notas sobre alcances e possibilidades. Cadernos Pagu, 39, 403-429.

Méllo, R. (2006). A construção da noção de abuso sexual infantil. Belém: EDUFPA.

Méllo, R., Silva, A., Lima, M., \& Di Paolo, A. (2007). Construcionismo, Práticas Discursivas e possibilidades de pesquisa em psicologia social. Psicologia \& Sociedade; 19 (3) 26-32.

Méllo, R. \& Sampaio, J. (2012). Corpos intersex borrando as fronteiras do discurso médico. Revista NUFEN, 4(1), 04-19).

Ministério da Saúde. (2007). Plano nacional de enfrentamento da epidemia de AIDS e das DST entre gays, HSH e travestis. Brasília: Autor.

Ministério da Saúde. (2009). Plano integrado de enfrentamento da feminização da epidemia de AIDS e das DST. Revisado. Brasília: Autor.

Ministério da Saúde. (2010). Política Nacional de Saúde Integral de Lésbicas, Gays, Bissexuais, Travestis e Transexuais. Brasília: Autor.

Miskolci, R. (2010). Não Somos, queremos: notas sobre o declínio do essencialismo estratégico. Mesa: Novas Perspectivas e Desafios Políticos Atuais do evento Stonewall $40+$ o que no Brasil? Salvador, 17 de setembro. Acesso em 16 setembro, $2012 \mathrm{em} \mathrm{http://www.ufscar.br/cis/wp-content/}$ uploads/N\%C3\%A3o-Somos-queremosRichardMiskolci. pdf

Miskolci, R. (2011). Não ao sexo rei: da estética da existência foucaultiana à política queer. In L. Sousa, T. Sabatine, \& B. Magalhães (Orgs.), Michel Foucault: sexualidade, corpo e direito. (pp. 47 - 68). Marília: Oficina Universitária; São Paulo: Cultura Acadêmica.

Pelúcio, L. (2007). Nos nervos, na carne, na pele: uma etnografia travesti sobre o modelo preventivo de AIDS. Tese Doutorado em Ciências Sociais. Programa de Pós-graduação em Ciências Sociais, Universidade Federal de São Carlos, São Carlos, SP.

Pelúcio, L. \& Miskolci, R. (2009). A prevenção do desvio: o dispositivo da AIDS e a repatologização das sexualidades dissidentes. Sexualidad, Salud y Sociedad: Revista Latinoamericana. 1, 125-157. 
Pereira, P. (2012). Queer nos trópicos. Revista Contemporânea, 2(2), $371-394$.

Preciado, B. (2002) Manifiesto contra-sexual - praticas subversivas de identidade sexual. Madri: Ed. Opera Prima.

Preciado, B. (2008) Testo Yonqui. Madri: Espanha Calpe.

Preciado, B. (2011). Multidões Queer - Notas para uma política dos 'anormais'. Estudos Feministas, 19(1), 11-20.

Secretaria Especial Dos Direitos Humanos. (2009). Plano Nacional de Promoção da Cidadania e Direitos Humanos de Lésbicas, Gays, Bissexuais, Travestis e Transexuais. Brasília: Autor.

Sedgwick, E. (2007) A epistemologia do armário. Cadernos Pagu, 28(1), 19-54.

Simões, J. \& Facchini, R. (2009). Na trilha do arco-íris: do movimento homossexual ao LGBT. São Paulo: Editora Fundação Perseu Abramo.

Spink, M. J. (2004) Práticas discursivas e produção de sentido no cotidiano: aproximações teóricas e metodológicas (3a. ed.). São Paulo: Cortez.

Spink, M. J. \& Medrado, B. (2004). Produção de sentidos no cotidiano: uma abordagem teórico-metodológica para análise das práticas discursivas. In M. J. Spink (Org.), Práticas discursivas e produção de sentido no cotidiano: aproximações teóricas e metodológicas. (3a. ed., pp.41-62) São Paulo: Cortez.

Spink, P. (2004). Análise de documentos de domínio público. In M. J. Spink. Práticas discursivas e produção de sentido no cotidiano: aproximações teóricas e metodológicas. (3a. ed., pp. 123-153). São Paulo: Cortez.

Weeks, J. (2001). O corpo e a sexualidade. In G. O. Louro. Corpo Educado: Pedagogias da Sexualidade. (pp. 37- 82). Belo Horizonte: Autêntica.

\section{Agradecimento}

À Capes pela concessão de bolsa DS - Mestrado à primeira autora.

Submissão em: 16/11/2012

Revisão em: 26/02/2014

Aceite em: 17/03/2014

Juliana Vieira Sampaio é Psicóloga e Doutoranda no Programa de Pós-Graduação em Psicologia da Universidade Federal de Pernambuco.

Endereço: Av. Professor Morais Rego, No 1235, Cidade Universitária. Recife/PE, Brasil. CEP 50670-901. E-mail: julianavsampaio@hotmail.com

Idilva Maria Pires Germano é Psicóloga, Doutora em Sociologia e Professora Associada do Programa de PósGraduação em Psicologia da Universidade Federal do Ceará. E-mail: idilvapg@gmail.com

\section{Como citar:}

Sampaio, J. V. \& Germano, I. M. P. (2014). Políticas públicas e crítica queer algumas questões sobre identidade LGBT. Psicologia \& Sociedade, 26(2), 290-300. 